\title{
Erratum to: A Categorical-Generative Theory of Social Processes: Towards the Ontological and Mathematical Foundations of a Grammar-Based Model for Qualitative Research
}

\author{
Bruno da Rocha Braga ${ }^{1,2(\bowtie)}($ (]) \\ ${ }^{1}$ Central Bank of Brazil, Brasília, DF 70074-900, Brazil \\ ${ }^{2}$ Federal Institute of Education, Science and Technology of Brasília, \\ Brasília, DF 73380-900, Brazil \\ bruno.rocha.braga@ifb.edu.br
}

\section{Erratum to: \\ Chapter "A Categorical-Generative Theory of Social Processes: Towards the Ontological and Mathematical Foundations of a Grammar-Based Model for Qualitative Research" in: A.P. Costa et al. (eds.), Computer Supported Qualitative Research, Advances in Intelligent Systems and Computing 621, DOI: 10.1007/978-3-319-61121-1_34}

In the original version of the book, the following corrections have been updated in Chapter 34:

Email address “bruno.rocha.braga@ifb.edu.br" has been positioned below "Federal Institute of Education, Science and Technology of Brasília, Brasília, DF 73380-900, Brazil".

Acknowledgements in Page 410 and the reference of "Fundação de Amparo à Pesquisa do Distrito Federal" have been removed.

The updated online version of this chapter can be found at http://dx.doi.org/10.1007/978-3-319-61121-1_34 